\title{
Evidence for two abrupt warming events of SST in the last century
}

\author{
Costas A. Varotsos ${ }^{1}$, Christian L. E. Franzke ${ }^{2}$, Maria N. Efstathiou ${ }^{1}$ and Andrei G. \\ Degermendzhi ${ }^{3}$
}

(1) Climate Research Group, Division of Environmental Physics and Meteorology, Faculty of Physics, University of Athens, University Campus Bldg. Phys. V, Athens, 15784, Greece

(2) British Antarctic Survey, Natural Environment Research Council, Cambridge, UK

(3) Institute of Biophysics, SB RAS, Russian Academy of Sciences,, Krasnoyarsk, Russia

*Corresponding author: Costas A. Varotsos Email: covar@phys.uoa.gr

\begin{abstract}
We have recently suggested that the warming in the sea surface temperature (SST) since 1900, did not occur smoothly and slowly, but with two rapid shifts in 1925/1926 and 1987/1988, which are more obvious over the tropics and the northern midlatitudes. Apart from these shifts most of the remaining SST variability is due to the El-Nino Southern Oscillation (ENSO) and the Pacific Decadal Oscillation (PDO). Here we provide evidence that the time separation between these two SST shifts (around 60 years) is almost equal to the quasi-periodicity of many natural cycles, like that of the PDO, the global and Northern Hemisphere (NH) annual mean temperature, the Atlantic Multi-decadal Oscillation (AMO), the Inter-Tropical Convergence Zone, the Southwest US Drought data, the length of day, the air surface temperature, the Atlantic meridional overturning circulation, and the change in the location of the centre of mass of the solar system. In addition, we show that there exists a strong seasonal link between SST and ENSO over the tropics and the NH midlatitudes, which becomes stronger in autumn of the Northern Hemisphere. Finally, we found that before and after each SST shift the intrinsic properties of the SST time series obey stochastic dynamics, which is unaffected by the modulation of these two shifts. In particular, the SST fluctuations for the time period between the two SST shifts exhibit 1/f-type long range correlations, which are frequently encountered in a large variety of natural systems. Our results have potential implications for future climate shifts and crossing tipping points due to an interaction of intrinsic climate cycles and anthropogenic greenhouse gas emissions.
\end{abstract}

\section{Introduction}

Nowadays, it is known that the climate system exhibits temporal variability spanning almost nine orders of magnitude (i.e., from 1 month to 50 million years) which is due to regular (deterministic) and irregular (stochastic) fluctuations (e.g., Grassl 2000, 2011; Markonis and Koutsoyiannis 2013). Understanding which part of the observed climate variability is due to deterministic and which due to stochastic fluctuations is important for seasonal and decadal climate forecasts, future climate predictions and climate trend analysis.

The quasi 60-year oscillation belongs to the regular fluctuations. Evidence for this oscillation was found by Schlesinger and Ramankutty (1994) and Zhen-Shan and Xian (2007) and has been shown to be among the most prominent climate variability components of the global and $\mathrm{NH}$ annual mean temperature and China in the period 1881 to 2002. Furthermore, Minobe (1997) found evidence for a 50-70 year climate oscillation over North America and the North Pacific. 
In this context, Knudsen et al. (2011) discussed the nature and origin of the Atlantic Multidecadal Oscillation (AMO) suggesting in particular that a quasi-persistent $\sim 55$-yr to 70-yr AMO, existed during large parts of the Holocene. This cycle is linked to internal oceanatmosphere variability and its length was found to be approximately 62 years with maxima around 1878, 1943 and 2004, and minima around 1912 and 1974. In other words, the AMO cycle behaves closely to that of the global temperature cycle in both the cycle length and extremes occurrence. Knudsen et al (2011) noticed that since the AMO obeys a 60-yr cycle, the Inter-Tropical Convergence Zone also exhibits a similar cycle.

The approximately 60-yr cycle is also detected in the Pacific Decadal Oscillation (PDO) given that it goes through warm and cool phases with the duration of about 30 years each (http://jisao.washington.edu/pdo/).

Chambers et al. (2012) studying the long tide gauge records in every ocean basin has reached the conclusion that there is a significant 60-yr oscillation in every ocean basin. A cycle of the approximate length of 64 yrs, has also been observed in the Southwest US Drought data with maxima around 1918 and 1982 and a minimum in 1955 (drought) (http://www.ncdc.noaa.gov/img/climate/research/2002/may/Reg107Dv00_palm06_01000502 _pg.gif).

According to the UN Food Agricultural Organization (FAO) report the direct observations (110-150 years) of the length of day (a geophysical index) clearly varies on a 55-65 yr cycle. In the same report it is stated that the reconstructed time series of the air surface temperatures during the last 1500 years obeys the same 55-65 yr cycle (http://www.fao.org/docrep/005/Y2787E/y2787e03a.htm).

Gray (2009) suggested that the 60-yr cycle is evident in the North Atlantic thermohaline circulation. This cycle is also evident in the time-series of the global ENSO and SST for 1850 - 2009 (http://www.jisao.washington.edu/data/globalsstenso/)

As far as to the irregular fluctuations of the climate system are concerned, it has long been recognised that despite the slow and gradual climate variability, rapid climate changes might be expected, since the climate system is in an unstable equilibrium (Brooks 1925; Humphrey 1932). In this connection, the report of the Intergovernmental Panel on Climate Change in 1995 stated the possibility of climate "surprises" - "Future unexpected, large, and rapid climate system changes (as have occurred in the past)" (IPCC 1996). It is still stated in the IPCC Fourth Assessment Report: Climate Change 2007 (in the section 2.5.2 Mitigation, adaptation and climate change impacts), notably: “... it is not clear that climate surprises have a low probability...” (IPCC 2007).

As pieces of evidence accumulated, a growing belief that climate is not equable but behaves as a complex system, with a temporal evolution in which a small, even random, forcing could trigger rapid and irreversible changes (so-called "tipping points" Lenton et al. 2007) that could be huge (Alley et al. 2003; Peavoy and Franzke 2010). In other words, the climate system can experience abrupt changes (Budyko 1962). In this regard, the Chicago "dishpan" experiments in the late 1950s had experimentally shown that the rotating liquid into a tabletop dishpan simulates well the circulation of the atmosphere which might abruptly change its circulation pattern (flipping between distinct modes) upon the occurrence of a small perturbation (Riehl and Fultz 1957, 1958).

For instance, as the Arctic tundra becomes warmer and the permafrost starts to melt which could potentially lead to increased greenhouse gas emissions of methane accelerating global warming (Foley 2005). This can start a feedback cycle which will accelerate the decrease in ice cover which will result in more solar radiation to be absorbed by the dark ground; which in turn will lead to the melting of more ice (Brooks 1925). Therefore, a small change in initial conditions would spark a self-sustaining transition between climate states, which might be abrupt, i.e. with jumps between climate regimes. The melting of Siberian permafrost has been identified as one of the tipping points by Lenton et al. (2007).

A compelling example of rapid climate shifts are the two rapid shifts (1925/1926 and 1987/1988) in the sea surface temperature (SST) that were recently detected by Belolipetsky 
et al. (2013) by analysing climate data during the period 1900-2012. In particular, they have suggested that during each sharp shift (masked by natural variability) the mean SST apparently had risen abruptly by about $0.28^{\circ} \mathrm{C}$ over the tropics $\left(30^{\circ} \mathrm{S}-30^{\circ} \mathrm{N}\right)$ and $0.36^{\circ} \mathrm{C}$ in the northern middle latitudes $\left(30^{\circ} \mathrm{N}-60^{\circ} \mathrm{N}\right)$. In addition, Belolipetsky et al. (2013) have reported that most of the remaining temperature variability is related to El-Nino Southern Oscillation (ENSO) and the PDO. This result confirms earlier findings by Varotsos (2013) according to which the ENSO signal in the SST field extends over tropics and subtropics, becoming maximal in the region around $30^{\circ} \mathrm{N}-30^{\circ} \mathrm{S}$.

The aim of the present study is to further explore the characteristics of the above-mentioned two rapid shifts in SST by investigating the intrinsic properties of SST, ENSO and PDO with modern tools of statistical physics.

\section{Data and analysis}

In the present study we have used the observed SST anomalies (SSTa) since 1948 that were provided by the NASA/GISS (http://data.giss.nasa.gov/gistemp/; Reynolds et al. 2002) and HadSST2 and Reynolds v2 since 1990 obtained from the Climate Explorer site (http://climexp.knmi.nl/select.cgi?id=someone@somewhere\&field=hadsst). The PDO index was obtained from (http://www.atmos.washington.edu/ mantua/abst.PDO.html) and depicts the leading principal component of monthly SST anomalies in the North Pacific Ocean, poleward of $20^{\circ} \mathrm{N}$.

As a proxy for ENSO we have used two sources of data. For the time period 1948-2012 we have used the Nino34 index, which is available from the NOAA Earth System Research Laboratory. For ENSO index during 1900-2012 we have used the HadISST1 dataset (http://climexp.knmi.nl/getindices.cgi?WMO=UKMOData/hadisst1_nino3.4a\&STATION=N INO3.4\&TYPE=i\&id=someone@somewhere).

For the investigation of the intrinsic time series properties of SSTa we employed the new tool of the Detrended Fluctuation Analysis (DFA) developed by Peng et al. (1994), which provides insight into long-range correlations (Franzke 2012 a, b) of non-stationary timeseries. The studied time series was detrended and deseasonalised by applying the $6^{\text {th }}$ degree polynomial detrending and the Wiener statistical method, respectively (Wiener 1950). A brief description of DFA may be given as follows:

1) The $y(i)=$ SST anomalies time-series is integrated and partitioned into a set of nonoverlapping boxes of equal length, $\tau$.

2) In each box a polynomial local trend is fitted, in order to detrend the integrated profile (by subtracting the locally fitted trend).

3) The root-mean-square fluctuations $F_{d}(\tau)$ of this integrated and detrended profile is calculated over all scales (box sizes). The detrended fluctuation function $F$ is defined by (Kantelhardt et al. 2002):

$$
F^{2}(\tau)=\frac{1}{\tau} \sum_{i=k \tau+1}^{(k+1) \tau}[y(i)-z(i)]^{2}, k=0,1,2, \ldots,\left(\frac{N}{\tau}-1\right),
$$

where $z(i)$ is a polynomial, of order $l$, least-square fit to the $\tau$ data contained within a box. For scaling dynamics, the averaged $F^{2}(\tau)$ over the $N / \tau$ intervals with length $\tau$ will be guided by a power law, notably:

$$
<F^{2}(\tau)>\sim \tau^{2 \alpha}
$$

and then the power spectrum function scales with $1 / f^{\beta}$, with $\beta=2 a-1$ (Ausloos and Ivanova 2001).

If the derived DFA-exponent is not equal to 0.5 ( $a \neq 0.5$ ), in a certain range of $\tau$ values, then long-range correlations exist in that interval, whereas the exponent $a=0.5$ demonstrates the classical random walk (white noise). If the $\alpha$-exponent is between zero and 0.5 , then powerlaw anticorrelations are present (antipersistence). If the $\alpha$-exponent is between 0.5 and 1 , then persistent power-law correlations prevail. The exponent $a=1$ denotes the so-called $1 / f$ 
noise. Finally, when $1<\alpha<1.5$, then long-range correlations are present (Weber and Talkner 2001). A more detailed description of the DFA tool is presented in Varotsos et al. (2009). To ensure the existence of the long range correlations the two criteria (i.e., the rejection of a simple exponential decay of the autocorrelation function and the establishment of the power-law scaling) as suggested by Maraun et al. (2004) must be satisfied.

\section{Results and Discussion}

\subsection{Step-wise SST warming over the last century}

According to Belolipetsky et al. (2013) the comparison between SSTa and ENSO time-series over the tropical regions $\left(30^{\circ} \mathrm{S}-30^{\circ} \mathrm{N}, 180^{\circ} \mathrm{W}-180^{\circ} \mathrm{E}\right)$ shows a significant correlation between them provided that a staircase-like function is applied on the SSTa values (Fig.1a). This function during the period 1900-2012 is a two-step function which equals around -0.28 before 1926, 0 between 1926 and 1987 and 0.28 after (Fig.1b). The subtraction of this twostep function from the SSTa time-series gives a new time-series, which matches well (cor. coef. $=0.86$ ) with the corresponding ENSO values.

\section{[Please insert figure 1 about here]}

The main finding obtained from Fig. 1 is that the increase in SST during 1900 - 2012 did not occur slowly and gradually, but abruptly in 1925/1926 and 1987/1988, thus confirming the views of Brooks (1925), Humphrey (1932) and Budyko (1962) described in the Introduction. It is worth noting that the same results as in the tropics were also obtained for the NH midlatitudes (Belolipetsky et al. 2013). Especially, most of the remaining temperature anomalies in the belt $30^{\circ} \mathrm{N}-60^{\circ} \mathrm{N}$ are mainly dominated by both ENSO and PDO. In other words, the superposition of the stair-case function (fig 1b) with the ENSO and PDO indices provides an extremely well fit to the observed SST.

This two-step function can be easily confirmed by using statistical break point analysis (for the three periods 1900-1925, 1926-1987 and 1988-2012) and the multivariate quantile regression analysis (e.g., Franzke 2013; Oosterbaan 1994). In this regard, Fig. 2 depicts SSTa time series compared to the multivariate linear quantile regression lines of the $95^{\text {th }}$ and $5^{\text {th }}$ percentiles and the multivariate linear least-squares regression, Inspection of Fig. 2 shows that there is a statistically significant impact of ENSO on the extremely low SSTa values (lower than the $5 \%$ percentile of data, which almost coincides with the 1st shift) as well as on the extremely high SSTa values (greater than the 95\% percentile of data, which almost coincides with the 2nd shift) (see table 1). Additionally, the horizontal interstitials of the left and right frames in Fig. 2 coincide with the $5^{\text {th }}$ (i.e., $-0.48{ }^{\circ} \mathrm{C}$ ) and the $95^{\text {th }}$ (i.e., $0.44{ }^{0} \mathrm{C}$ ) percentiles of SSTa. It is noteworthy that according to Belolipetsky et al. (2013) the amplitudes for the two shifts are $-0.26{ }^{\circ} \mathrm{C}$ and $0.28{ }^{\circ} \mathrm{C}$ for the tropics, while $0.38{ }^{\circ} \mathrm{C}$ and $0.34{ }^{\circ} \mathrm{C}$ for northern middle latitudes. In addition, Belolipetsky et al. (2013) concluded that the temperature rise is around $0.28{ }^{\circ} \mathrm{C}$ in tropics and $0.36{ }^{\circ} \mathrm{C}$ over the northern middle latitudes under the assumption that the two shifts generate equal changes to SSTa.

[Please insert figure 2 about here]

[Please insert table 1 about here]

Furthermore, examining the hypothesis of equal slopes $(b)$ and intercepts $(a)$ for the linear least squares regression lines of SSTa vs. time (in the three periods 1900-1925, 1926-1987 and 1988-2012) the following is derived: $\mathrm{H}_{0}: b_{1926-1987}=b_{1988-2012}$ can not be rejected at $95 \%$ level, however, $\mathrm{H}_{1}: a_{1926-1987}=a_{1988-2012}$ can not be accepted at $95 \%$ level. In other words, the regression lines that correspond to 1926-1987 and 1988-2012 periods seem to be parallel with significantly distinct intercepts (Kleinbaum and Kupper 1978). On the other hand, the Mann- 
Whitney and Kolmogorov-Smirnov non-parametric tests demonstrate that the hypothesis $\mathrm{H}_{2}$ : $m_{1926-1987}=m_{1988-2012}$ (where $m$ denotes SSTa mean value) can not be accepted at $95 \%$ level, thus indicating a statistically significant 'shift' of the SSTa time series between these two periods. The same statistical analysis, for the first two periods (1900-1925, 1926-1987), resulted in rejection of the hypothesis $\mathrm{H}_{0}: b_{1900-1925}=b_{1926-1987}, \mathrm{H}_{1}: a_{1900-1925}=a_{1926-1987}$ and $\mathrm{H}_{2}$ : $m_{1900-1925}=m_{1926-1987}$ revealing, once more, a statistically significant 'shift' of SSTa time series between the first two periods.

\subsection{The seasonal link between SST and ENSO}

\subsubsection{The belt $30^{\circ} \mathrm{S}-30^{\circ} \mathrm{N}$}

As noted above Belolipetsky et al. (2013) suggested that a high correlation between SSTa and ENSO time-series is achieved when a two-step function is first added on the monthly mean ENSO values over the tropics and the NH mid-latitudes.

It is interesting to investigate whether any preference exists for the link between ENSO and SST before taking into account this two-step function. In this context, Table 2 shows that the link between ENSO and SST over the tropics throughout the period 1948-2012 is stronger when the Sun is located on the autumnal equinox (the seasonal attribution is that of the Northern Hemisphere). Fig. 3 illustrates the geographical distribution of the correlation coefficient between ENSO and SST over the tropics, where the centres of its maximum and minimum values are also depicted.

[Please insert table 2 about here]

[Please insert figure 3 about here]

In the following, we repeated the same investigation as above but for the time period 19481987 (just before the jump of ENSO) and 1988-2012 (just after the jump of ENSO). The results obtained are shown in Tables 3, 4, respectively. The conclusion drawn from Tables 3 , 4 is the same with that of Table 1, notably: the link between ENSO and SST over the tropics is stronger during autumn independently of the time period, i.e., just before and after the SST leap of 1987/1988. This means that the forcing that resulted in the SST shift did not substantially change the nature of the SST and ENSO variability. The comparison of the correlation coefficients between ENSO and SST over the tropics that is reported in Tables 3, 4 reveals that the autumnal maximum becomes stronger just after the occurrence of the SST shift of 1987/1988 (Fig. 4).

[Please insert figure 4 about here]

[Please insert table 3, 4 about here]

\subsubsection{The belt $30^{\circ} \mathrm{S}-60^{\circ} \mathrm{N}$}

The analysis performed for the belt $30^{\circ} \mathrm{S}-30^{\circ} \mathrm{N}$ and described above, is herewith repeated for the belt $30^{\circ} \mathrm{S}-60^{\circ} \mathrm{N}$.

Tables 5, 6, 7 show the seasonal variability of the correlation coefficient between ENSO and SST for the entire time period 1948-2012 as well as for the periods before and after the abrupt shift of SST in 1988/1989.

The prominent outcome from Tables 5, 6, 7 is that the link between ENSO and SST is stronger during autumn, thus confirming the same result obtained for the tropical region. 
Thus, in sub-sections 3.3.1 and 3.3.2 the spatial pattern of the ENSO influence to the SST field is depicted. Similar figures and Tables as above could be produced by subtracting first the ENSO signature from the spatial SST field in the three periods (1900-1925, 1926-1987, 1988-2012) separately, in order to investigate the spatial pattern of the two shifts. However, it will be reported in a forthcoming paper.

\subsection{Did the abrupt increases in SST affect its intrinsic properties?}

Now we want to address whether the shifts in SSTa have changed the stochastic properties of the time series. We hypothesize that if the intrinsic time series properties stay the same before and after the shifts than it is likely that the shifts are an intrinsic feature of the climate system.

Keeping this in mind and to gain deeper insight into the processes taking place we proceed first to the exploration of the intrinsic properties of SSTa throughout the time period 19002012. For this purpose we employ the DFA tool described above. Then, we repeat the same analysis of the SSTa for the time periods before and after the action of the two ENSO shifts (in 1925/1926 and 1987/1988). The results obtained are illustrated in the Figs. 5a, b, c, d.

[Please insert figure 5 about here]

Inspection of Figs. 5a, b, c, d reveals that before and after the two-step action on the SST the slopes of the straight lines are very close to that obtained for the entire time period 19002012. Therefore, the intrinsic properties of the SST time series are not be affected by the modulation of the two SST shifts. The latter finding points to the fact that the causal effect for the existence of the two abrupt shifts is closely associated with the natural mechanisms with which the climate system is operating. Another factor that plays an important role in our thinking is the value of the slopes by themselves. All the slopes derived from Fig. 5a, b, c, d are very close to unity, suggesting the existence of $1 / \mathrm{f}$-type power-law correlations (longmemory). It should be remembered that such a $1 / \mathrm{f}$-signal is found in a large variety of systems, e.g., condensed matter systems, granular flow, DNA sequence, ionic current fluctuations in membrane channels, chaotic quantum systems, human cognition and coordination, burst errors in communication systems, electrical measurements, the electric noise in carbon nanotubes and in nanoparticle films, the occurrence of earthquakes, the seismic electric signals, signals arising from cooperative orientation of electric dipoles, etc (Sarlis et al. 2009).

It is worth emphasizing that the complete investigation of long-term memory in SST should be accompanied with the establishment of the power-law scaling and the rejection of a simple exponential decay of the autocorrelation function (Maraun et al. 2004; Varotsos et al. 2003a, b, 2005a, b, 2006, 2007, 2008, 2009, 2012; Varotsos and Kirk-Davidoff 2006). In this context, Fig. 6a shows that the best fit of the power spectral density of SSTa (during 19261987 ) is initially exponential, while for larger scales it turns into an algebraically (power-law) fit. Therefore, the first criterion suggested by Maraun et al. (2004) is fulfilled. In addition, Fig. 6b illustrates the constancy of "local slopes" in a certain range towards the low frequencies, thus satisfying the second criterion of Maraun et al. (2004). Consequently, the existence of the long range correlations is ensured for the period between the two shifts in SSTa (i.e. 1926-1987) only. Interestingly, these two criteria are not fulfilled before and after the period 1926-1987 by making the existence of the long range correlations precarious before and after the period between the two abrupt shifts. It may probably be attributed to the limited length of the time series before and after these shifts.

[Please insert figure 6 about here] 


\section{Conclusions}

From the analysis and discussion quoted above the following conclusions are drawn:

1) The increase in SST over $30^{\circ} \mathrm{S}-60^{\circ} \mathrm{N}$ during 1900 - 2012 did not occur slowly and gradually, but abruptly in 1925/1026 and 1987/1988 with time-separated events by 62 years, i.e., an interval reminiscent of the well established quasi-60yr natural cycle.

2) A strong seasonal link between SST and ENSO over the tropics and NH midlatitudes exists, which becomes strongest in autumn.

3) Before and after the above-mentioned two shifts in SST, the intrinsic properties of the SST time series seem to be unaffected by the modulation of these two shifts. Hence, the plausible forcing that resulted in the SST shifts did not alter the nature of the SST and ENSO variability.

4) The SST fluctuations exhibit 1/f-type power-law correlations which can be established only in the time period between the two shifts in SST.

5) Our results suggest that the SST shifts are an intrinsic property of the climate system.

As mentioned above the two shifts in the temporal evolution of the SST have occurred in $1925 / 1926$ and 1987/1988. Therefore, the time separation between these two shifts is around 62 years, which is reminiscent of the cycle length of 62 years in the global temperature anomalies (with maxima around 1879, 1942 and 2002, and minima around 1910 and 1972). This intrinsic mode of climate variability has not been taken account of in precious climate change studies. This could have led to a possible overestimation of deterministic climate trends. Further studies are needed to elucidate the role of the 60 year cycle in climate change. Further studies are also needed to elucidate whether this 60 year mode is intrinsic to the climate system (e.g. an oceanic oscillation) or whether solar and planetary cycles (Scafetta 2010, 2012) are responsible. This calls also for the use and procurement of longer climate records because most instrumental records cover only the last 150 years and thus just resolve only 2 complete cycles of the 60 year mode.

Our results suggest the potential for future rapid increases in global mean temperatures due to the interaction of intrinsic climate cycles/shifts and anthropogenic greenhouse gas emissions. This raises also the prospect of crossing tipping points in the future; for instance a shutdown of the Atlantic Meridional Overturning Circulation or the sudden release of Methane from the Arctic tundra due to a thawing of permafrost with its negative impacts on economies and societies.

\section{References}

Alley RB, Marotzke J, Nordhaus WD, Overpeck JT, Peteer DM, Pielke RS, Pierrenhumbert RT, Rhines PB, Stocker TF, Talley LD, Wallace JM (2003) Abrupt climate change. Science 299:2005-2010.

Ausloos M, Ivanova K (2001) Power-law correlations in the southern - oscillation - index fluctuations characterizing El Nino. Phys Rev E. doi:10.1103/PhysRevE.63.047201

Belolipetsky PV, Bartsev SI, Degermendzhi AG, Hsu HH, Varotsos CA (2013) Empirical evidence for a double step climate change in twentieth century. http://arxiv.org/ftp/arxiv/papers/1303/1303.1581.pdf

Brooks CEP (1925) The Problem of Mild Polar Climates. Quart J Roy Meteorol Soc, 51:8394

Budyko MI (1962) Some Ways of Influencing the Climate. Meteor I Gidrol 2:3-8

Chambers DP, Merrifield MA, Nerem RS (2012) Is there a 60-year oscillation in global mean sea level? Geophys Res Lett 39, L18607. doi:10.1029/2012GL052885

Foley JA (2005) Tipping Points in the Tundra. Science 310:627-628. doi: 10.1126/science.1120104.

Franzke C (2012a) On the statistical significance of surface air temperature trends in the Eurasian Arctic region. Geophys Res Lett 39, L23705. doi:10.1029/2012GL054244. 
Franzke C (2012b) Nonlinear Trends, Long-Range Dependence, and Climate Noise Properties of Surface Temperature. J Climate 25:4172-4183. doi: 10.1175/JCLI-D-1100293.1

Franzke C (2013) A novel method to test for significant trends in extreme values in serially dependent time series. Geophys Res Let. doi: 10.1002/grl.50301

Grassl H (2000) Status and Improvements of Coupled General Circulation Models. Science 288:1991-1997 DOI: 10.1126/science.288.5473.1991

Grassl H (2011) Climate Change Challenges. Surv 32:319-328 DOI: 10.1007/s10712-0119129-z

Gray WM (2009) Climate change: Driven by the ocean - not humans. The Steamboat Institute Conference, Steamboat Springs, Colorado, August 29, 2009. http://tropical.atmos.colostate.edu/Includes/Documents/Presentations/graysteamboat2009. ppt

Humphreys WJ (1932) This Cold, Cold World. Atlantic:749-54

IPCC (1996) Climate Change 1995: The Science of Climate Change. edited by J.T. Houghton et al. Cambridge: Cambridge University Press

IPCC (2007) Climate Change 2007, the Fourth Assessment Report (AR4) of the United Nations Intergovernmental Panel on Climate Change (IPCC) (Cambridge: Cambridge University Press).

Kantelhardt JW, Zschiegner SA, Koscielny-Bunde E, Havlin S, Bunde A, Stanley HE (2002) Multifractal detrended fluctuation analysis of nonstationary time series. Phys A 316:87114

Kleinbaum DG, Kupper LL (1978) Applied regression analysis and other multivariable methods. Boston:Duxbury

Knudsen MF, Seidenkrantz MS, Jacobsen BH, Kuijpers A (2011) Tracking the Atlantic Multidecadal Oscillation through the last 8,000 years. Nature Commun 2, Article number:178 doi:10.1038/ncomms1186

Lenton TM, Held H, Kriegler E, Hall JW, Lucht W, Rahmstorf W, Schellnhuber HJ (2008) Tipping elements in the Earth's climate system. PNAS 105:1786-1793. doi: 10.1073/pnas.0705414105

Maraun D, Rust HW, Timmer J (2004) Tempting long-memory - on the interpretation of DFA results. Nonlin Process Geophys 11:495-503

Markonis Y, Koutsoyiannis D (2013) Climatic Variability Over Time Scales Spanning Nine Orders of Magnitude: Connecting Milankovitch Cycles with Hurst-Kolmogorov Dynamics. Surv Geophys 34:181-207. doi 10.1007/s10712-012-9208-9

Minobe, S. (1997) A 50-70 year climatic oscillation over the North Pacific and North America. Geophys. Res. Lett., 24, 683-686. DOI: 10.1029/97GL00504

Oosterbaan RJ (1994) Chapter 6 in: H.P.Ritzema (Ed.), Drainage Principles and Applications, Publication 16, second revised edition, 1994, International Institute for Land Reclamation and Improvement (ILRI), Wageningen, The Netherlands. ISBN 9070754339

Peavoy D, Franzke C (2010) Bayesian analysis of rapid climate change during the last glacial using Greenland delta O-18 data. Climate of the past 6:787-794. doi: 10.5194/cp-6-7872010

Peng CK, Buldyrev SV, Havlin S Simons M, Stanley HE, Goldberger AL (1994) Mosaic organization of DNA nucleotides. Phys Rev E 49(2):1685-1689

Reynolds GP, Zhang ZJ, Zhang XB (2002) Association of antipsychotic drug-induced weight gain with a polymorphism of the promoter region of the 5-HT2C receptor gene. Lancet 359:2086-2087

Riehl R, Fultz D (1957) Jet-stream and long waves in a steady rotating-dishpan experiment: Structure of the circulation. Quart J Roy Meteorol Soc, 83 (356):215-231

Riehl R, Fultz D (1958)The general circulation in a steady rotating dishpan experiment. Quart J Roy Meteorol Soc 84:389-417

Sarlis NV, Skordas ES, Varotsos PA (2009) Heart rate variability in natural time and 1/f “noise”. EPL 87 18003. doi: 10.1209/0295-5075/87/18003 
Scafetta N (2010) Empirical evidence for a celestial origin of the climate oscillations and its implications. J Atmos \& Solar-Ter Phys. doi:10.1016/j.jastp.2010.04.015

Scafetta N (2012) Testing an astronomically based decadal-scale empirical harmonic climate model versus the IPCC (2007) general circulation climate models. J Atmos \& Solar-Ter Phys 80:124-137 doi: 10.1016/j.jastp.2011.12.005

Schlesinger ME, Ramankutty N (1994) An oscillation in the global climate system of period 60-70 years. Nature 367:723-726

Varotsos C (2005a) Airborne measurements of aerosol, ozone, and solar ultraviolet irradiance in the troposphere. J Geophys Res 110(D9), D09202. doi: 10.1029/2004JD005397

Varotsos C (2005b) Power-law correlations in column ozone over Antarctica. Int J Remote Sens 26(16):3333-3342

Varotsos C, Assimakopoulos MN, Efstathiou M (2007) Technical Note: Long-term memory effect in the atmospheric $\mathrm{CO}_{2}$ concentration at Mauna Loa. Atmos Chem Phys 7:629-634

Varotsos C, Efstathiou M, Tzanis C (2009) Scaling behaviour of the global tropopause. Atmos Chem Phys 9:677-683

Varotsos C, Efstathiou M, Tzanis C, Deligiorgi D, (2012) On the limits of the air pollution predictability; the case of the surface ozone at Athens, Greece. Environ Sci Pollut Res 19 (1):295-300. doi: 10.1007/s11356-011-0555-8

Varotsos C, Kirk-Davidoff D (2006) Long-memory processes in ozone and temperature variations at the region 60 degrees S-60 degrees N. Atmos Chem Phys (6):4093-4100

Varotsos C, Ondov J, Efstathiou M (2005) Scaling properties of air pollution in Athens, Greece and Baltimore, Maryland. Atmos Environ 39:4041- 4047

Varotsos C, Efstathiou M, Tzanis C (2009) Scaling behaviour of the global tropopause. Atmos Chem Phys 9:677-683

Varotsos CA, Milinevsky G, Grytsai A, Efstathiou M, Tzanis C (2008) Scaling effect in planetary waves over Antarctica. Int J Rem Sens 29 (9):2697-2704

Varotsos CA (2013) The global signature of the ENSO and SST-like fields. Theor Appl Climatol. doi 10.1007/s00704-012-0773-0

Varotsos CA, Ondov JM, Cracknell AP, Efstathiou MN, Assimakopoulos MN (2006) Longrange persistence in global Aerosol Index dynamics. Int J Rem Sens 27(16):3593- 3603

Varotsos PA, Sarlis NV, Skordas ES (2003a) Long-range correlations in the electric signals that precede rupture: Further investigations. Phys Rev E. doi: 10.1103/PhysRevE.67.021109

Varotsos PA, Sarlis NV, Skordas ES (2003b) Attempt to distinguish electric signals of a dichotomous nature. Phys Rev E. doi:10.1103/PhysRevE.68.031106

Weber RO, Talkner P (2001) Spectra and correlations of climate data from days to decades. J Geophys Res 106:20131-20144

Wiener N (1950) Extrapolation, Interpolation and Smoothing of Stationary Time Series. MIT Technology Press and John Wiley and Sons, New York

Zhen-Shan and Xian (2007) Multi-scale analysis of global temperature changes and trend of a drop in temperature in the next 20 years. Meteor Atmos Phys 95. http://www.springerlink.com/content/g28u12g2617j5021/ 


\section{FIGURES}

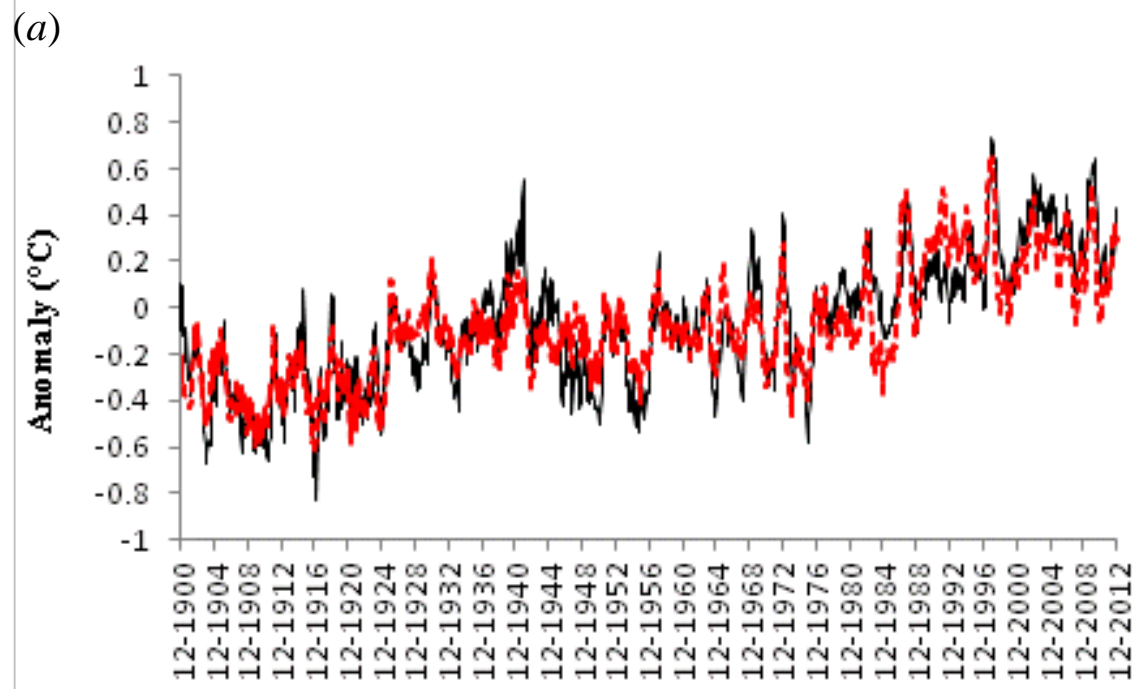

(b)

Month

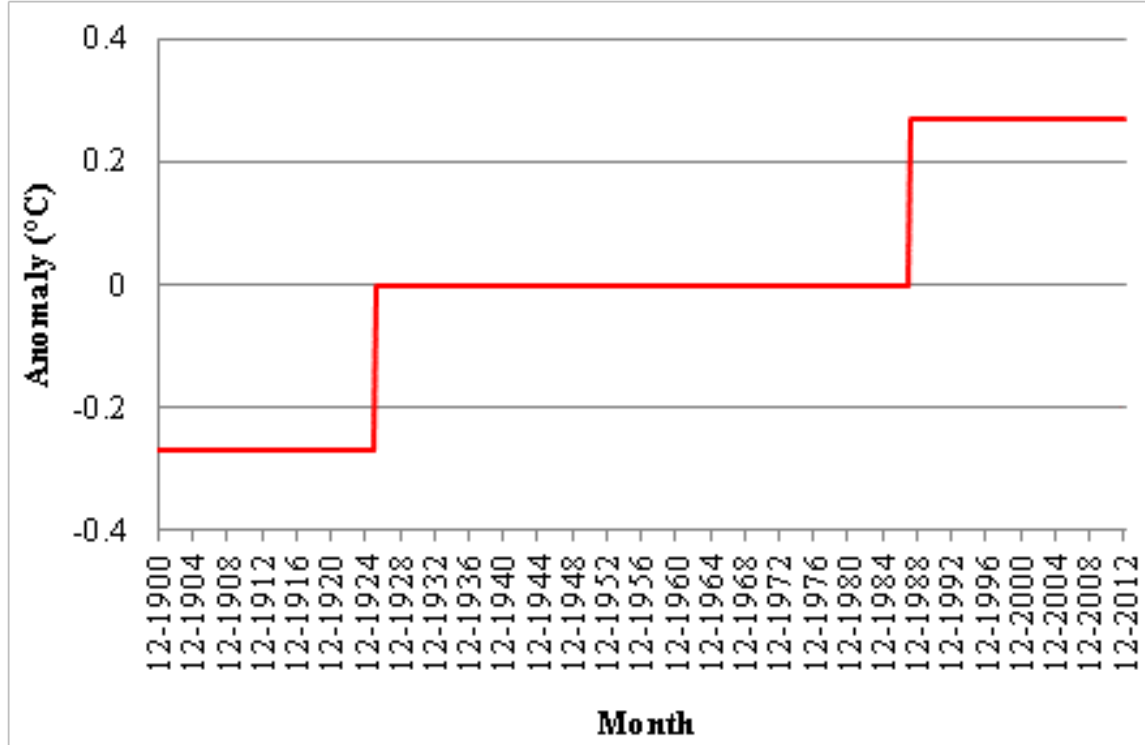

Fig. 1 (a) SSTa over tropics (black line) and ENSO after linear regression (red dotted line) throughout the 1900-2012 period, according to the stair-case function (leaps) shown in (b). 


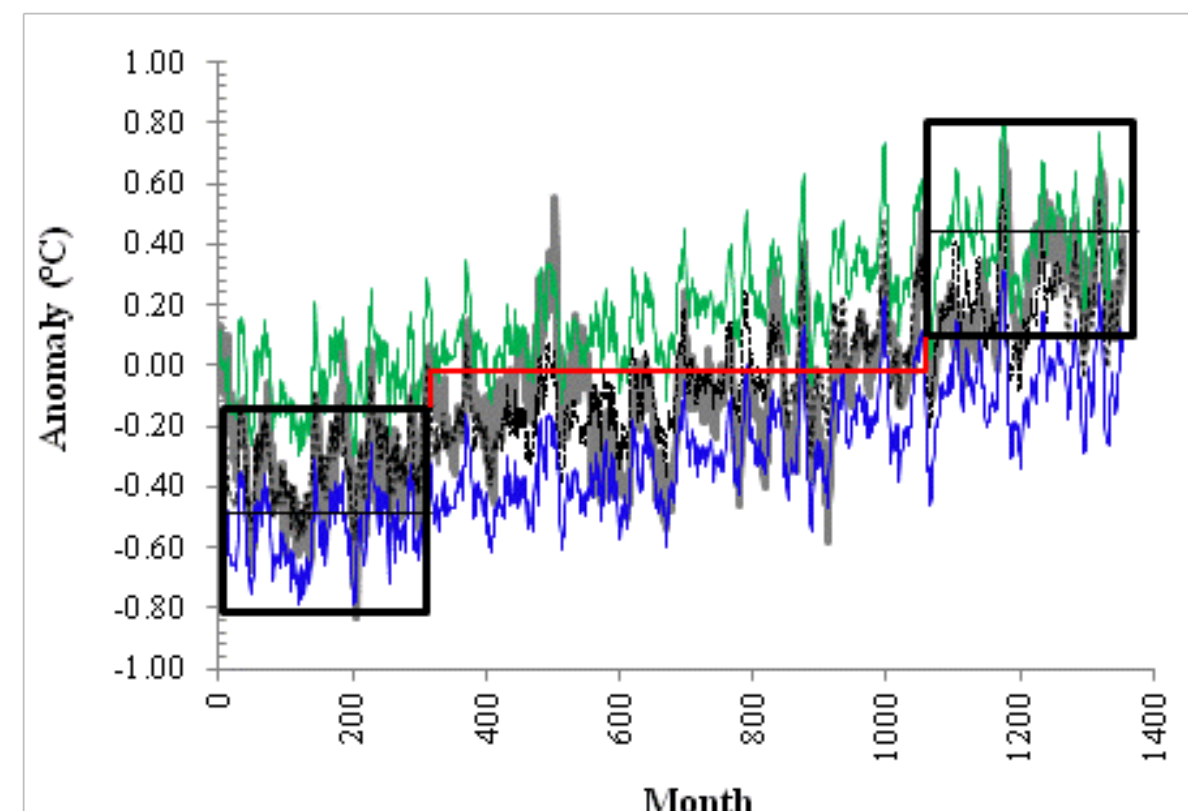

Fig. 2 SSTa time series (grey line), the multivariate linear quantile regression lines of the $95^{\text {th }}$ and $5^{\text {th }}$ percentiles (green and blue line, respectively) and the multivariate linear least-squares regression (dotted black line). The left frame indicates the correlation of SSTa with the $5^{\text {th }}$ percentile regression before the $1^{\text {st }}$ shift, while the right frame indicates the correlation of SSTa with the $95^{\text {th }}$ percentile regression after the $2^{\text {nd }}$ shift. The horizontal interstitial of the left frame coincides with the $5^{\text {th }}$ percentile of SSTa (i.e., $-0.48{ }^{\circ} \mathrm{C}$ ), while the corresponding one of the right frame coincides with the $95^{\text {th }}$ percentile of SSTa (i.e., $0.44{ }^{\circ} \mathrm{C}$ )
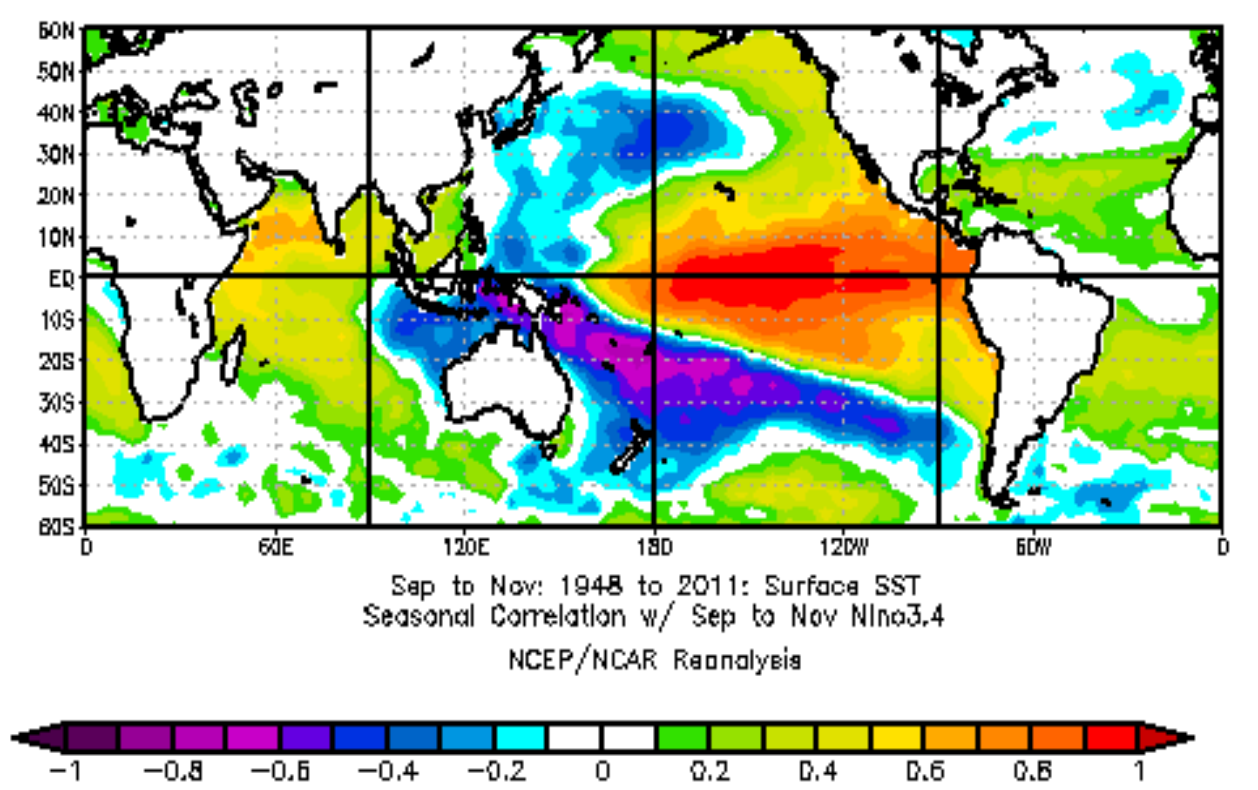

Fig. 3 The longitude/latitude pattern of the correlation coefficient between ENSO and SST over tropics for the autumn season, throughout the period 1948-2012. 


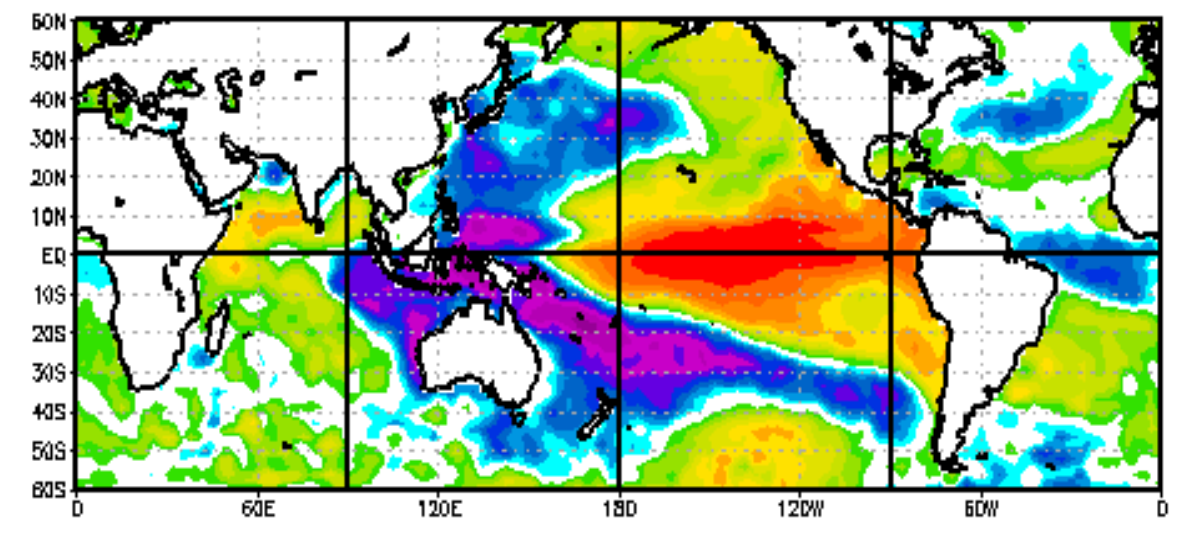

Sep to Nov: 1988 to 2012: Surface 5ST

Seosonal comelation $W /$ Sep to Nov NInoJ.4 NCEP/NCAR Rennalyeis

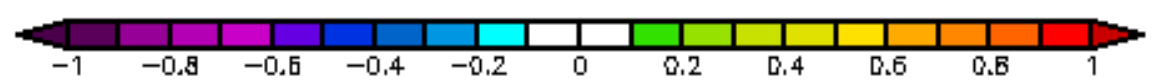

Fig. 4 The longitude/latitude pattern of the correlation coefficient between ENSO and SST over tropics for the autumn season, for the period (1988-2012) just after the ENSO jump (in 1987/1988).
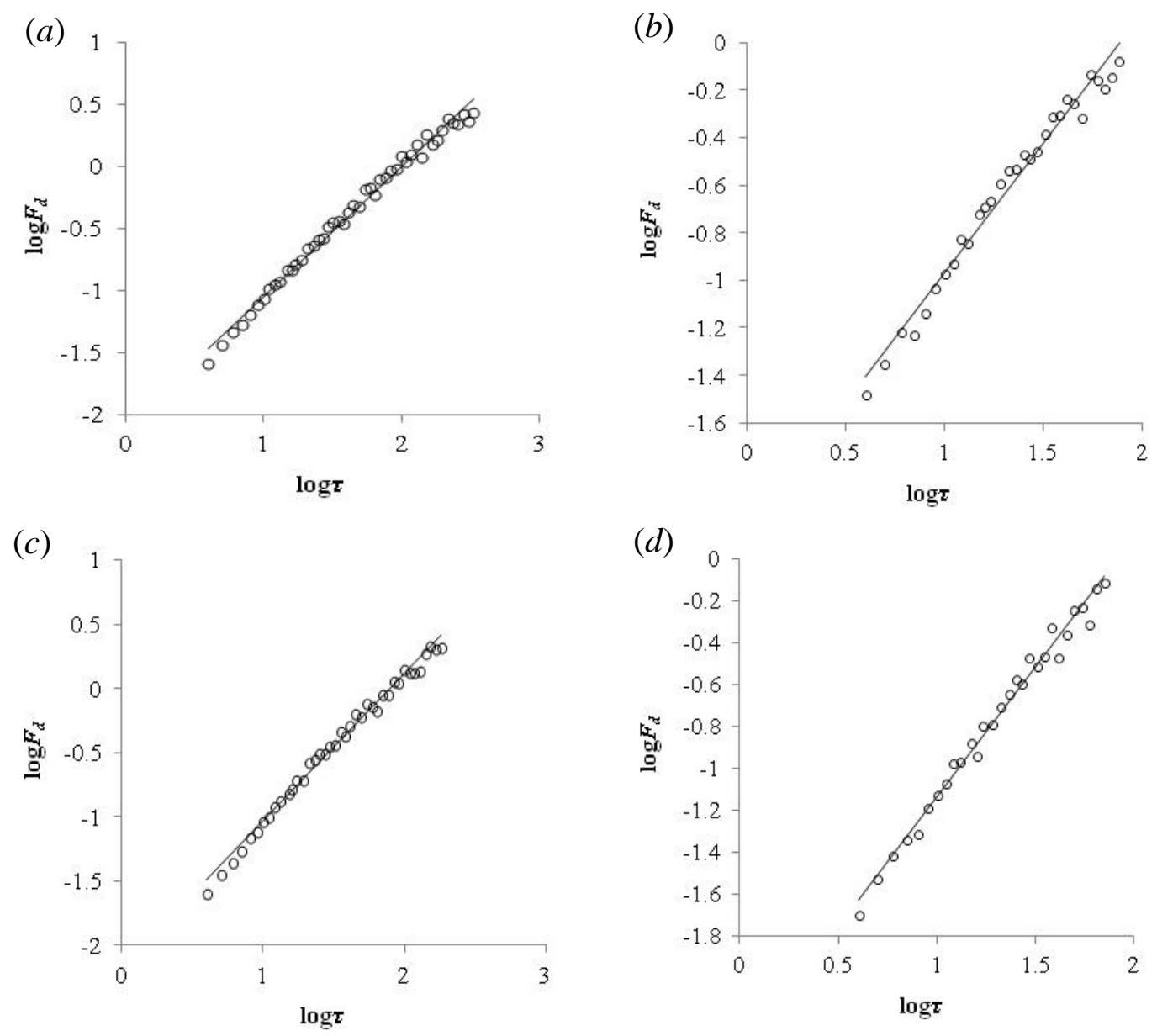

Fig.5 Log-log plot of the root-mean-square fluctuation function $\left(F_{d}(\tau)\right)$ versus time interval $\tau$ (in month) for the SSTa time series and the corresponding best fit equation during (a) 1900$2012\left(y=1.05 x-2.09\right.$ with $\left.R^{2}=0.99\right)$, (b) 1900-1925 $\left(y=1.1 x-2.06\right.$ with $\left.R^{2}=0.98\right)$, (c) 1926-1987 $\left(y=1.15 x-2.19\right.$ with $\left.R^{2}=0.99\right),(d) 1988-2012\left(y=1.23 x-2.37\right.$ with $R^{2}=$ $0.99)$. 

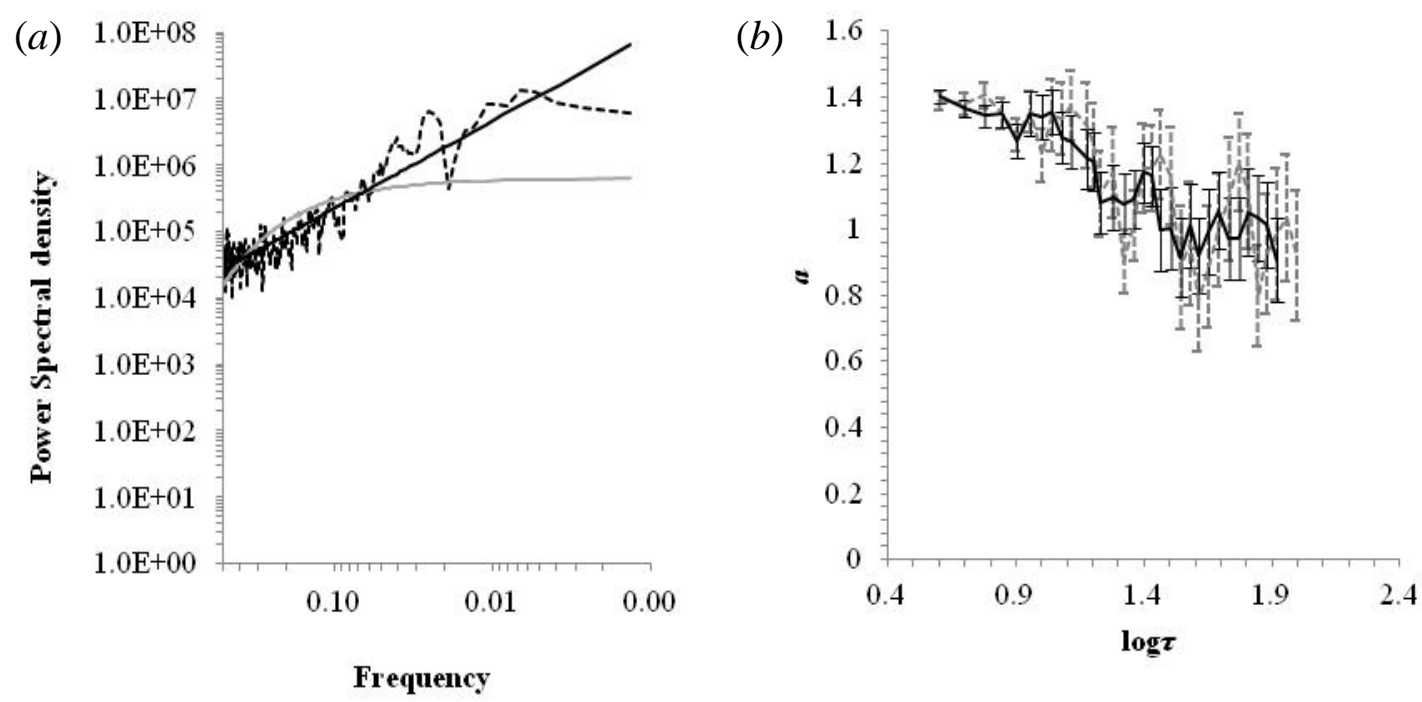

Fig. 6 (a) Power spectral density of the SSTa (during 1926-1987) with the power-law (black line) and the exponential (grey line) fit $\left(y=10845 x^{-1.32}\right.$ with $R^{2}=0.83$ and $y=630799 e^{-7.38 x}$ with $R^{2}=0.58$, respectively). The frequency-axis is in logarithm scale. (b) Local slopes of the $\log F_{d}(\tau)$ vs. $\log \tau$ calculated within a window of 8 points (dashed grey line) and 10 points (solid black line) for the SSTa time series. The error bars indicate the corresponding $1.96 \cdot \mathrm{s}_{\mathrm{a}}$ intervals of the slopes over all the considered scales. 


\section{TABLES}

Table 1 Coefficients of the multivariate linear quantile regression of the $95^{\text {th }}$ and $5^{\text {th }}$ percentiles and the multivariate linear least-squares regression (LLSR) for SSTa over the latitude belt $30^{\circ} \mathrm{S}-30^{\circ} \mathrm{N}$. All coefficients are significant at $95 \%$ confidence interval

\begin{tabular}{|c|c|c|c|}
\hline & $95^{\text {th }}$ percentile & $5^{\text {th }}$ percentile & LLSR \\
\hline Month & 0.00045 & 0.00046 & 0.0005 \\
\hline ENSO & 0.16150 & 0.15555 & 0.1590 \\
\hline Intercept & -0.11977 & -0.61966 & -0.4119 \\
\hline
\end{tabular}

Table 2 Seasonal correlation between SST and ENSO for the latitude belt $30^{\circ} \mathrm{S}-30^{\circ} \mathrm{N}$

\begin{tabular}{|c|c|c|c|c|c|}
\hline $\begin{array}{c}\text { Correlation } \\
\text { coef. }\end{array}$ & DJF & MAM & JJA & SON & $\begin{array}{c}\text { Annual } \\
\text { mean }\end{array}$ \\
\hline Maximum & 0.9727 & 0.9248 & 0.9482 & 0.9768 & 0.9653 \\
\hline Minimum & -0.6120 & -0.6933 & -0.5772 & -0.7467 & -0.5889 \\
\hline
\end{tabular}

Table 3 Seasonal correlation between SST and ENSO for the latitude belt $30^{\circ} \mathrm{S}-30^{\circ} \mathrm{N}$ (1948-1987)

\begin{tabular}{|c|c|c|c|c|c|}
\hline $\begin{array}{c}\text { Correlation } \\
\text { coef. }\end{array}$ & DJF & MAM & JJA & SON & $\begin{array}{c}\text { Annual } \\
\text { mean }\end{array}$ \\
\hline Maximum & 0.9636 & 0.9115 & 0.9447 & 0.9718 & 0.9538 \\
\hline Minimum & -0.7001 & -0.6908 & -0.6859 & -0.7542 & -0.6753 \\
\hline
\end{tabular}

Table 4 Seasonal correlation between SST and ENSO for the latitude belt $30^{\circ} \mathrm{S}-30^{\circ} \mathrm{N}$ (1988-2012)

\begin{tabular}{|c|c|c|c|c|c|}
\hline $\begin{array}{c}\text { Correlation } \\
\text { coef. }\end{array}$ & DJF & MAM & JJA & SON & $\begin{array}{c}\text { Annual } \\
\text { mean }\end{array}$ \\
\hline Maximum & 0.9920 & 0.9723 & 0.9817 & 0.9936 & 0.9929 \\
\hline Minimum & -0.7989 & -0.8410 & -0.7550 & -0.8432 & -0.7681 \\
\hline
\end{tabular}

Table 5 Seasonal correlation between SST and ENSO for the latitude belt $30^{\circ} \mathrm{S}-60^{\circ} \mathrm{N}$ (1948-2012)

\begin{tabular}{|c|c|c|c|c|c|}
\hline $\begin{array}{c}\text { Correlation } \\
\text { coef. }\end{array}$ & DJF & MAM & JJA & SON & $\begin{array}{c}\text { Annual } \\
\text { mean }\end{array}$ \\
\hline Maximum & 0.9724 & 0.9245 & 0.9475 & 0.9767 & 0.9579 \\
\hline Minimum & -0.6147 & -0.6909 & -0.5774 & -0.7350 & -0.6048 \\
\hline
\end{tabular}

Table 6 Seasonal correlation between SST and ENSO for the latitude belt $30^{\circ} \mathrm{S}-60^{\circ} \mathrm{N}$ (1948-1987)

\begin{tabular}{|c|c|c|c|c|c|}
\hline $\begin{array}{c}\text { Correlation } \\
\text { coef. }\end{array}$ & DJF & MAM & JJA & SON & $\begin{array}{c}\text { Annual } \\
\text { mean }\end{array}$ \\
\hline Maximum & 0.9590 & 0.9115 & 0.9447 & 0.9719 & 0.9538 \\
\hline Minimum & -0.6295 & -0.6908 & -0.6859 & -0.7542 & -0.6751 \\
\hline
\end{tabular}

Table 7 Seasonal correlation between SST and ENSO for the latitude belt $30^{\circ} \mathrm{S}-60^{\circ} \mathrm{N}$ (1988-2012)

\begin{tabular}{|c|c|c|c|c|c|}
\hline $\begin{array}{c}\text { Correlation } \\
\text { coef. }\end{array}$ & DJF & MAM & JJA & SON & $\begin{array}{c}\text { Annual } \\
\text { mean }\end{array}$ \\
\hline Maximum & 0.9900 & 0.9723 & 0.9817 & 0.9916 & 0.9909 \\
\hline Minimum & -0.8418 & -0.8410 & -0.7551 & -0.8432 & -0.7681 \\
\hline
\end{tabular}

